\title{
3D Numerical simulations of elastomeric bearings for bridges
}

\author{
Davide Forcellini ${ }^{1}$
}

Received: 27 August 2016/ Accepted: 7 November 2016/Published online: 21 November 2016

(C) Springer International Publishing Switzerland 2016

\begin{abstract}
Multilayer elastomeric isolation can be considered a well-known solution with many applications in the last 20 years in the infrastructure arena. In particular, isolation has been extensively applied for pier and abutment protection, in order to strengthen bridges against earthquakes. Elastomeric bearings can be subjected to large axial loads and lateral displacements during strong earthquakes, which induce potentially buckling effects. The recent Forcellini and Kelly (J Eng Mech 140(6):04014036, 2014) model allows to take into account large deformation response of a bearing when buckling occurs. This paper aims at verifying this theory using experimental results and numerical simulations. First of all, test results are taken from Nagarajaiah and Ferrell (J Struct Eng 125:946-954, 1999) and compared with the developed theory. Then, numerical simulations have been performed by applying OpenSees.
\end{abstract}

Keywords Elastomeric bearings - Bridges - Isolation · OpenSees · Buckling

\section{Introduction}

Past earthquakes all over the world have shown that the piers are the most sensitive parts of a bridge and their damage can be responsible for the collapse of the bridge spans. Therefore, pier protection should be considered as one of the most important goals for bridge protection and

Davide Forcellini

davide.forcellini@unirsm.sm

1 Università di San Marino, Via Salita alla Rocca 44, Montegiardino, San Marino strengthening against earthquakes. As shown by Makris and Zhang [19] and Morgan and Mahin [21], seismic isolation is conceivably one of the most promising alternatives especially in post-earthquake rehabilitation. Several studies by Vlassis and Spyrakos [28] and Tongaonkar and Jangid [26] show the benefic effects of the isolation technique on bridge safety and design costs. Other studies by Ucak and Tsopelas [27] and Forcellini [10], analyzed the importance of considering non-linear hysteretic behaviors for the isolation systems.

This paper aims at modelling multilayered elastomeric bearings, widely used in civil engineering as seismic isolators for bridges. Generally, the bearings are used in the case of compression and somewhere in presence of shear force. Therefore, it is necessary to have an accurate knowledge of the behavior of such devices under these kinds of load conditions. In this regard, buckling has been widely investigated with experimental tests, such as $[1-7,15,16,24,31]$ and numerical simulations $[22,25,29,30,32]$.

Recently Forcellini and Kelly [12] described the buckling phenomenon extending the original two-spring model of the bearing, developed by Kelly [13] and [17] to large deformations. The model is used to illustrate the influence of large deformations on the interaction between horizontal and vertical loads and assessing the post-buckling behavior of these bearings. In particular, the previous study was conducted with the aim to extend the original linear theory of multilayered elastomeric bearings by replacing the differential equations by the algebraic ones. The model has been recently performed in order to study some applications [10].

This paper aims firstly at comparing several test results with the developed theory. In particular, results (under compression and shear loads) from Nagarajaiah and Ferrell 
[22] were considered and compared with the theoretical approach. In this regard, the actual state of mechanical computations, allows investigating high non-linear behaviors with sophisticated numerical tools.

The paper aims at calibrating a 3D finite element (FE) model able to reproduce elastomeric bearings complex behavior. In particular, OpenSees (Open System for Earthquake Engineering simulations) by the Pacific Earthquake Engineering Research (PEER) center has been applied here in order to reproduce elastomeric bearings' three-dimensional behavior. The finite element (FE) model has been reproduced with a layered system able to represent the alternating steel and rubber layers and the bolted connections. OpenSees is able to simulate realistic lateral boundaries built up by assuming shear beam conditions in order to reproduce the shear effect between the two materials. During lab tests, non-linear behaviors have been registered, as shown by Nagarajaiah and Ferrell [22]. In order to take into account such behavior, calibrated finite element models can be used as powerful tools.

\section{Theoretical model}

The two-spring model (shown in Fig. 1) consists of two rigid elements in the shape of tees, connected by moment springs across hinges at the top and bottom and by shear springs and frictionless rollers at midheight [12]. The deformation variables shown are the shear displacement $(s)$, the relative rotation $(\theta)$ and the horizontal displacement (v). The vertical load is $P$ while the horizontal load at the top of the column is $F$. Following the formulation by Forcellini and Kelly [12], the kinematic at the top of the column in terms of horizontal displacement is defined by Eq. (1), where $h$ is the height of the model. Equilibrium conditions allow calculating $\theta$ from Eq. (2). The horizontal displacement can be evaluated by applying Eq. (3), fixing $\lambda$ and $p$ and solving for $f$ as a function of the calculated $\theta$.

$v=h \cdot \sin \theta+s \cdot \cos \theta$

$(p \cdot \cos \theta+\lambda) \cdot(p \cdot \sin \theta+f \cdot \cos \theta)=0$

$\frac{v}{h}=\sin \theta+\frac{1}{\lambda}(p \cdot \sin \theta+f \cdot \cos \theta)$

where:

$P_{E}=\frac{\pi^{2} \cdot E \cdot I_{S}}{h^{2}} \quad\left(E I_{S}\right.$ bending stiffness $)$

$P_{S}=G \cdot A_{s}\left(G A_{S}\right.$ effective shear stiffness $)$

$p=\frac{P}{\sqrt{P_{E} P_{S}}} ; f=\frac{F}{\sqrt{P_{E} P_{S}}} ; \lambda^{2}$

$=\frac{P_{S}}{P_{E}}$ (usually between 0.001 and 0.05 )

In this paper, the multilayer elastomeric bearing has been taken from the ones tested by Nagarajaiah and Ferrell [22] and named 302 (square: width $B=5$ in $(127 \mathrm{~mm})$, $h=4.385$ in $(111.4 \mathrm{~mm})$, shape factor $S=5,8$ rubber layers (thickness: $0.25 \mathrm{in}, 6.35 \mathrm{~mm}$ total) and 7 steel shims (thickness: 0.055 in, $1.397 \mathrm{~mm}$ total), as shown in Fig. 2. The bearing has a rubber cover of $0.125 \mathrm{in} .(3.18 \mathrm{~mm})$ and 1 in. $(25.4 \mathrm{~mm})$ thick end plates. The axial load was varied: 20 kip $(89 \mathrm{kN}), 30 \mathrm{kip}(133 \mathrm{kN})$ and $40 \mathrm{kip}(188 \mathrm{kN}), 50$ kip $(222 \mathrm{kN})$. The mechanical characteristics (shear modulus $\mathrm{G}$ and bulk modulus $\mathrm{K}$ ) of the rubber have been taken as 1.4 and $2000 \mathrm{MPa}$, respectively, in according with the values considered by Nagarajaiah and Ferrell [22]. Table 1 shows the characteristics of the bearings. Figure 3 shows the shear force-displacement relationship as a function of axial load, as calculated by the theoretical model. It is

Fig. 1 Two-spring model [12]

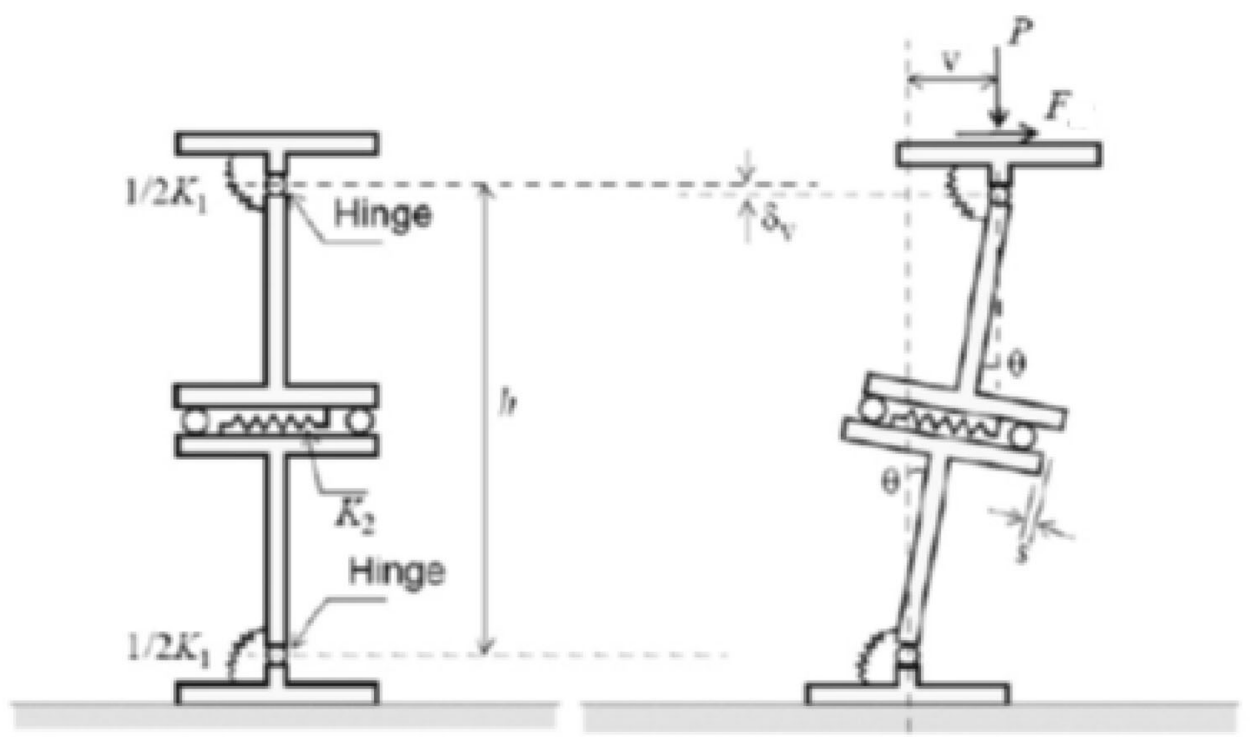




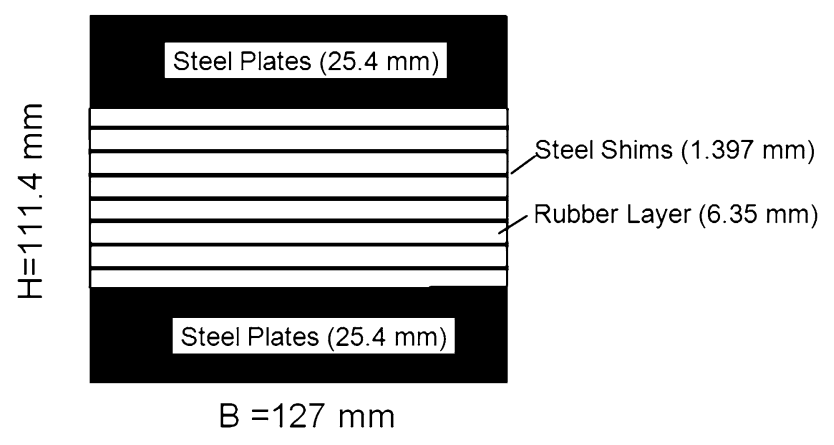

Fig. 2 Elastomeric bearing

possible to see that the displacements increase linearly with the lateral shear force. The axial load affects the stiffness that decreases with increasing axial load.

\section{Lab test model}

Shear force-horizontal displacement (F-v curves) from Nagarajaiah and Ferrell [22] have been here reproduced and compared first with the theoretical approach and then with numerical simulations. In particular, the F-v relationship has been calculated as a function of axial load for the specific type of bearing (named 302). The axial load was varied in the study: 20 kip $(89 \mathrm{kN}), 30 \mathrm{kip}(133 \mathrm{kN})$ and 40 kip $(188 \mathrm{kN}), 50 \mathrm{kip}(222 \mathrm{kN})$.

The results show that the force increases with the displacement but after a certain level of deformation, the force starts decreasing. Secondly, the shear force and horizontal displacement at which the maximum occurs decrease with increasing axial load. This non-linear behavior has been compared with the analytical results predicted by Forcellini and Kelly [12] in Fig. 4. Several considerations can be taken. First of all, the theory is able to catch the influence of the axial load. In particular, when the axial load increases, the stiffness decrease, as resulted from the tests. Secondly, in the first part of the curve, the theoretical approach can predict lab tests with good correspondence.

The comparison generally shows that analytical solutions have a satisfactory agreement with the test results for small values of force and displacements, at least when the relationship can be considered linear. After the peak value is reached, the theory loses its representativeness and is not able to describe the tested behavior because the structural parts such as hinges and beams start to register non-linear behaviors. In order to consider non-linear effects, Nagarajaiah and Ferrell [22] introduce a formulation to

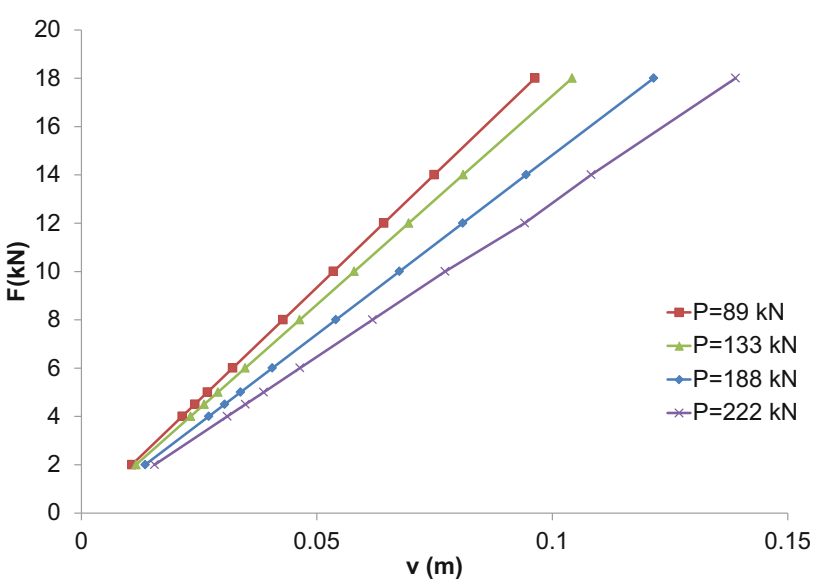

Fig. 3 Shear force-displacement curve following Forcellini and Kelly [12]

vary $\mathrm{G}$ as a function of the displacement. In particular, this variation was estimated empirically from the horizontal tangential stiffness, resulting from quasi-static tests. This paper, instead, aims at performing the tested behavior, by applying a highly non-linear software such as OpenSees (Open System for Earthquake Engineering Simulation) by Mazzoni et al. [20]. In this regard, the next paragraph details the finite 3D model applied in the study.

\section{Numerical simulations}

This paragraph aims at reproducing lab test responses of the selected elastomeric bearings with a 3D numerical model. The finite element model (Fig. 5) was built with OpenSees [20], by the Pacific Earthquake Engineering Research (PEER) Center. This platform allows high level of advanced capabilities for modelling and analyzing nonlinear responses of systems using a wide range of material models, elements and solution algorithms. The paper applies the interface named OpenSeesPL (http://soilquake. net/openseespl/) that was developed at University of California, San Diego, by Lu et al. [18]. It consists of a framework originally calibrated for soil analyses. Here it has been modified by considering a layered bearing instead of a layered soil.

The adopted 3D $(0.127 \mathrm{~m} \times 0.127 \mathrm{~m} \times 0.1114 \mathrm{~m})$ FE mesh is composed of 19,272 brickUP linear isoparametric 8-node elements with 20,202 nodes (Fig. 5). The model base boundary is set at a depth of $0.1114 \mathrm{~m}$ and was considered with a fixed conditions. Lateral boundaries were set as a shear type, in order to simulate the typical shear deformation

Table 1 Characteristics of the studied bearing

\begin{tabular}{llllllll}
\hline$A\left[\mathrm{~m}^{2}\right]$ & $G[\mathrm{MPa}]$ & $K[\mathrm{MPa}]$ & $t_{\mathrm{R}}[\mathrm{m}]$ & $S$ & $\begin{array}{l}P_{\mathrm{E}} \\
{[\mathrm{kN}]}\end{array}$ & $\begin{array}{l}P_{\mathrm{S}} \\
{[\mathrm{kN}]}\end{array}$ & $\lambda^{2}$ \\
\hline 0.016 & 1.40 & 2000 & 0.0508 & 5 & 6000 & 26.72 & 0.00445 \\
\hline
\end{tabular}



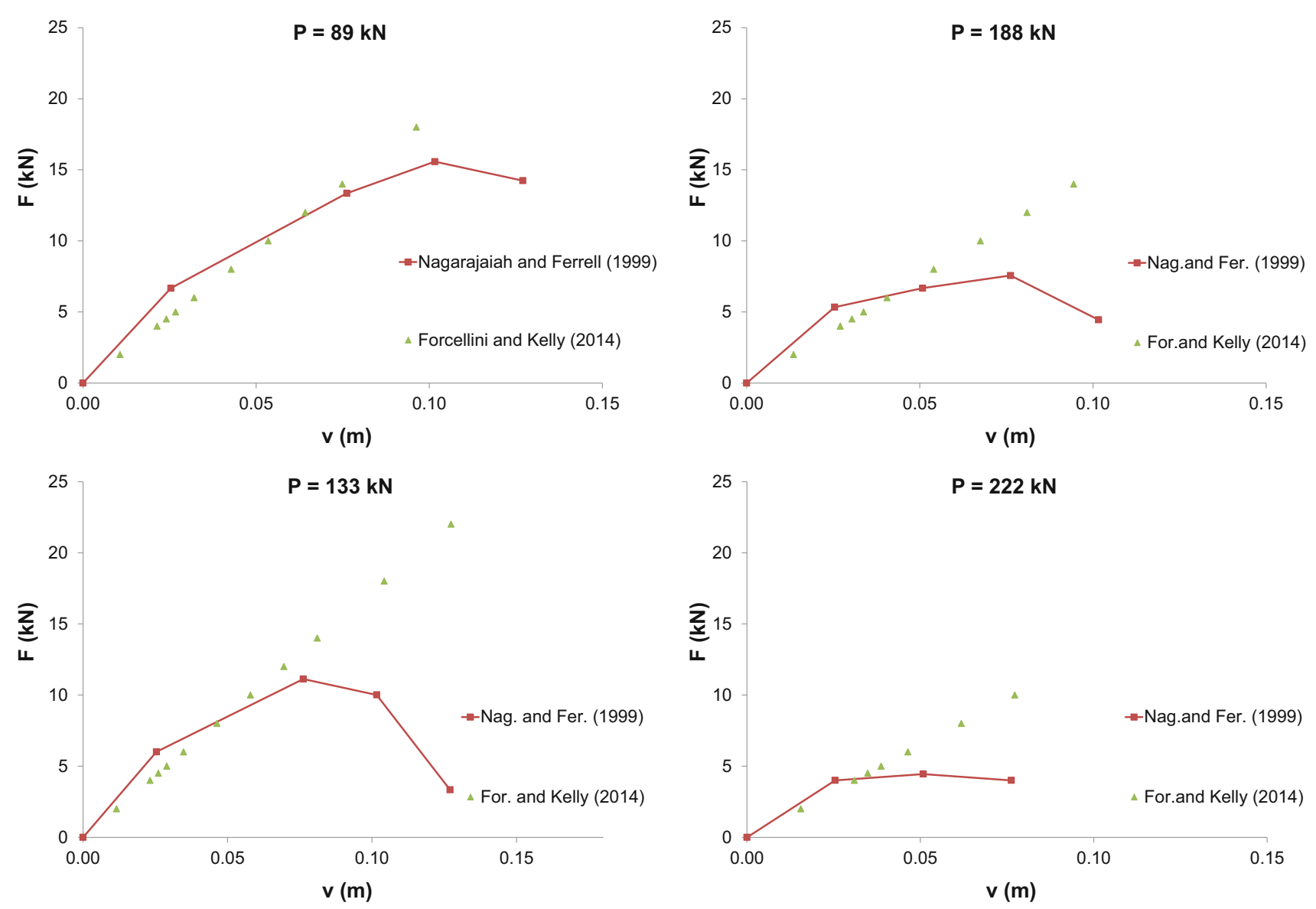

Fig. 4 Comparison between test results from Nagarajaiah and Ferrell [22] and theoretical results predicted by Forcellini and Kelly [12]

of elastomeric bearings. For all analyses, the Newmark transient integrator is used (with $\gamma=0.6$ and $\beta=0.3$ ). Stiffness and mass proportional damping is added with a $2 \%$ equivalent viscous damping at 1 and $6 \mathrm{~Hz}$.

Based on previous studies [11], two materials have been considered, by applying the defined Pressure Independent Multiyield model. It consists of a nonlinear hysteretic material, using a Von Mises multi-surface kinematic plasticity approach together with an associate flow rule [23]. It allows controlling the magnitude of permanent shear strain accumulation [33]. Non-linear shear stressstrain backbone curve is represented by a hyperbolic relation, which is defined by low-strain shear modulus and ultimate shear strength constants.

The performed analysis aims at reproducing the test conditions under which the elastomeric bearings have been originally tested. In this regards, pushover analyses (displacement-based method) were performed. In particular, final displacements have been assigned at the top nodes. All the nodes at the top level were tied together in order to represent a rigid plate and thus they move at the same quantity as the final displacement. The corresponding stress and strain in the various layers have been calculated and the resultant forces deduced directly from the interface.
Numerical simulations were performed in two steps. In the first, both materials (rubber and steel) have been assumed linear. In the second, steel has been still considered linear while rubber has been modelled with different non-linear assumptions detailed in 4.2.

\section{Step 1 (linear model)}

The first step consists in performing the model with linear assumptions in order to reproduce the theoretical results from Forcellini and Kelly [12]. Table 2 details the characteristics for the rubber and the steel shims (in terms of shear modulus, $\mathrm{G}$ and bulk modulus $\mathrm{K}$ ). The values for the rubber have been taken from those proposed by Nagarajaiah and Ferrell [22]. Figure 6 shows the backbone (linear) curves considered for the rubber and steel, respectively. Figure 7 shows shear strain in correspondence with the rubber and the steel layer. It is possible to verify that the deformations are concentrated in the rubber, as expected. The entity of such deformation corresponds to the ratio between the applied longitudinal displacement and the height of the rubber $\left(t_{\mathrm{R}}\right.$ in Table 1$)$. This means that the model is able to represent the imposed deformations. 


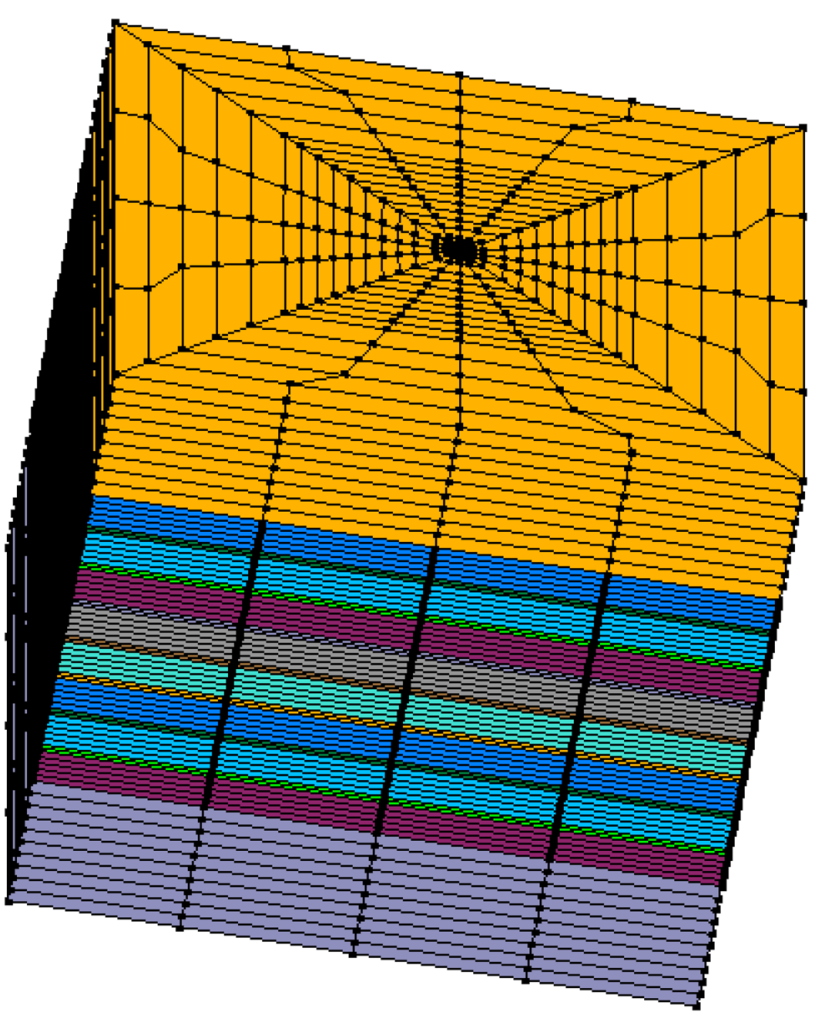

Fig. 5 3D FEM model

Longitudinal displacements are shown in Fig. 7 and they show a shear-type behavior, as expected.

Figure 8 shows that elastic assumptions allow obtaining results that are close to the theoretical approach. Therefore, theoretical formulation in terms of large deformation is able to represent correctly the behavior (such as shear deformations) when linear assumptions are made. On the other side, these numerical simulations (with linear assumptions) cannot represent the non-linear behavior that resulted from the tests (Table 2).

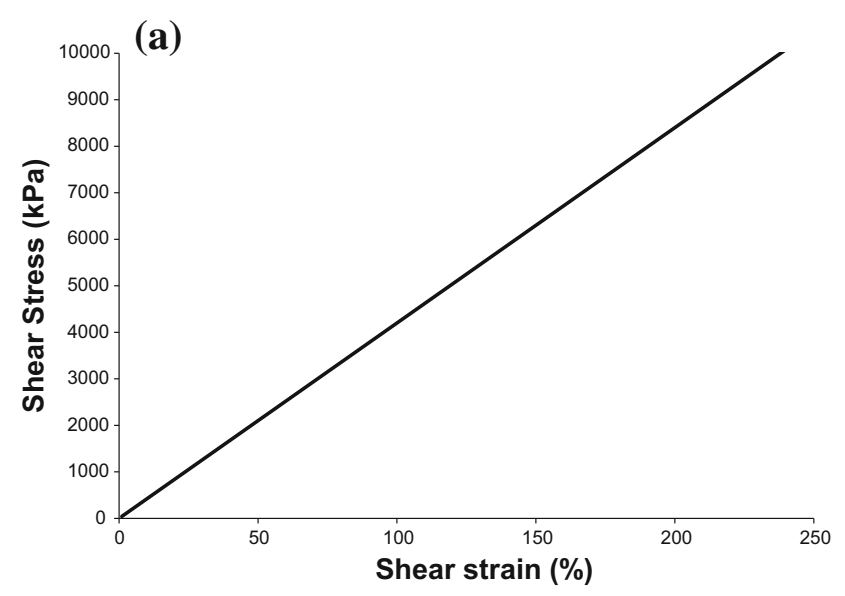

Fig. 6 Backbone curve-step 1 [rubber (a), steel (b)]

\section{Step 2 (non-linear model)}

In the second step, the material named Pressure Independent Multiyield [20] has been calibrated in order to represent the non-linear behavior described during lab tests. In particular, steel material has been maintained with the same characteristics of the first step. Rubber has been modelled as a non-linear hysteretic material with a Von Mises multi-surface kinematic plasticity model. In this regard, focus is on reproduction of the hysteretic elastoplastic shear response (including permanent deformations). In this material, plasticity is exhibited only in the deviatoric stress-strain response. The volumetric stress-strain response is linear-elastic and independent of the deviatoric response. Plasticity is formulated based on the multi-surface (nested surfaces) concept, with an associative flow rule. The non-linear shear stress-strain backbone curve is represented by the hyperbolic relation, defined by two material constants (low-strain shear modulus and ultimate shear strength).

The parameters adopted for the rubber were calibrated in order to take into account the decreasing of the shear forces with the increasing of the displacements. As it was built up, the material is able to catch the non-linear increase of force but not the degradation after the peak value. In particular, the peak value has been defined as the tension after which cavitation is supposed to start. This level of stress was set equal to $3 \mathrm{G}$ and maintained constant. Table 3 shows the values that have been calibrated. In particular, $\mathrm{C}$ is the shear stress peak value that is reached in correspondence with the shear strain named p. $n$ is the number of yield surfaces considered. Figure 9 shows the theoretical Von Mises multi-surface in principal stress space and the shear stress-strain backbone curve adopted for the rubber.

Figure 10 shows the shear force-displacement curves obtained from the numerical simulations. First of all, it is

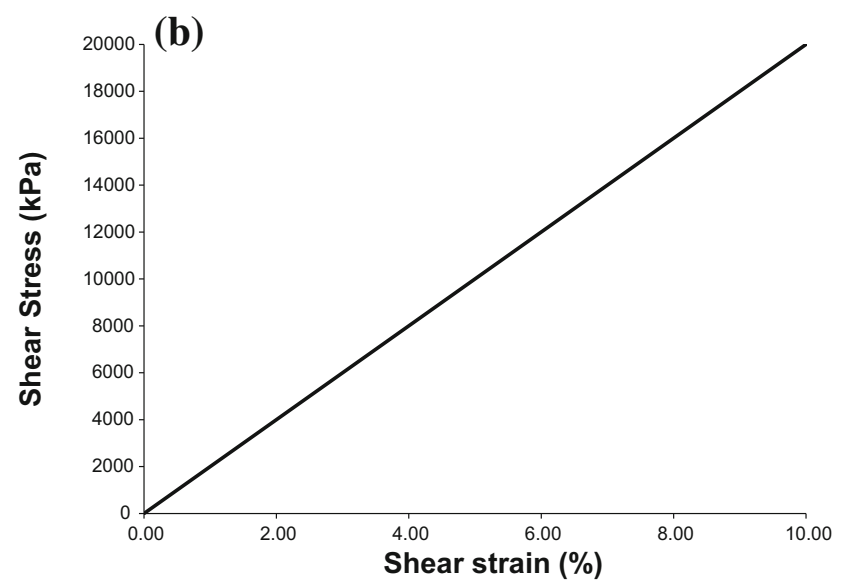


(a)

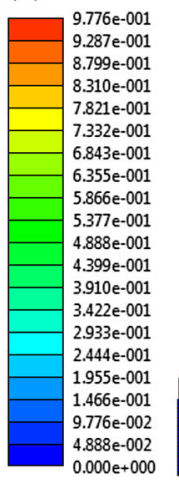

(b)

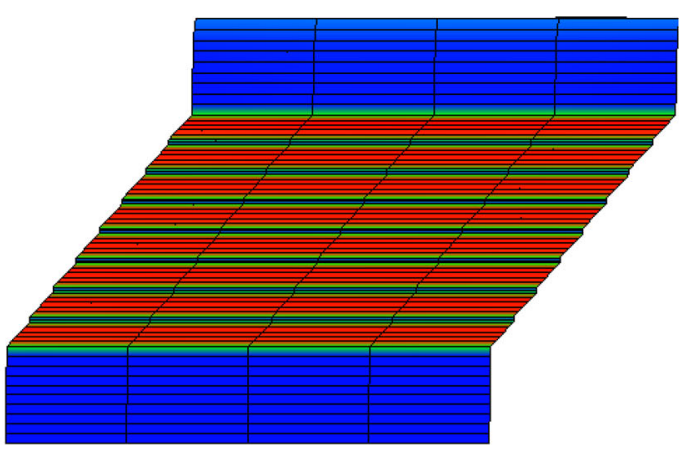

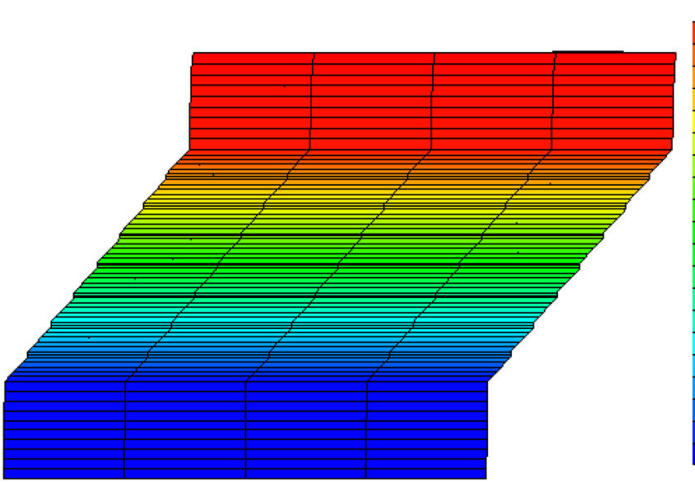

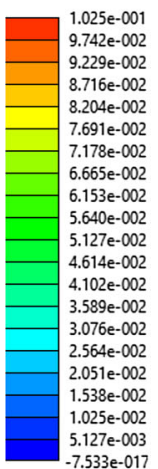

Fig. 7 Output. a shear strain (last step) and b displacements (last step, scale 1:1)
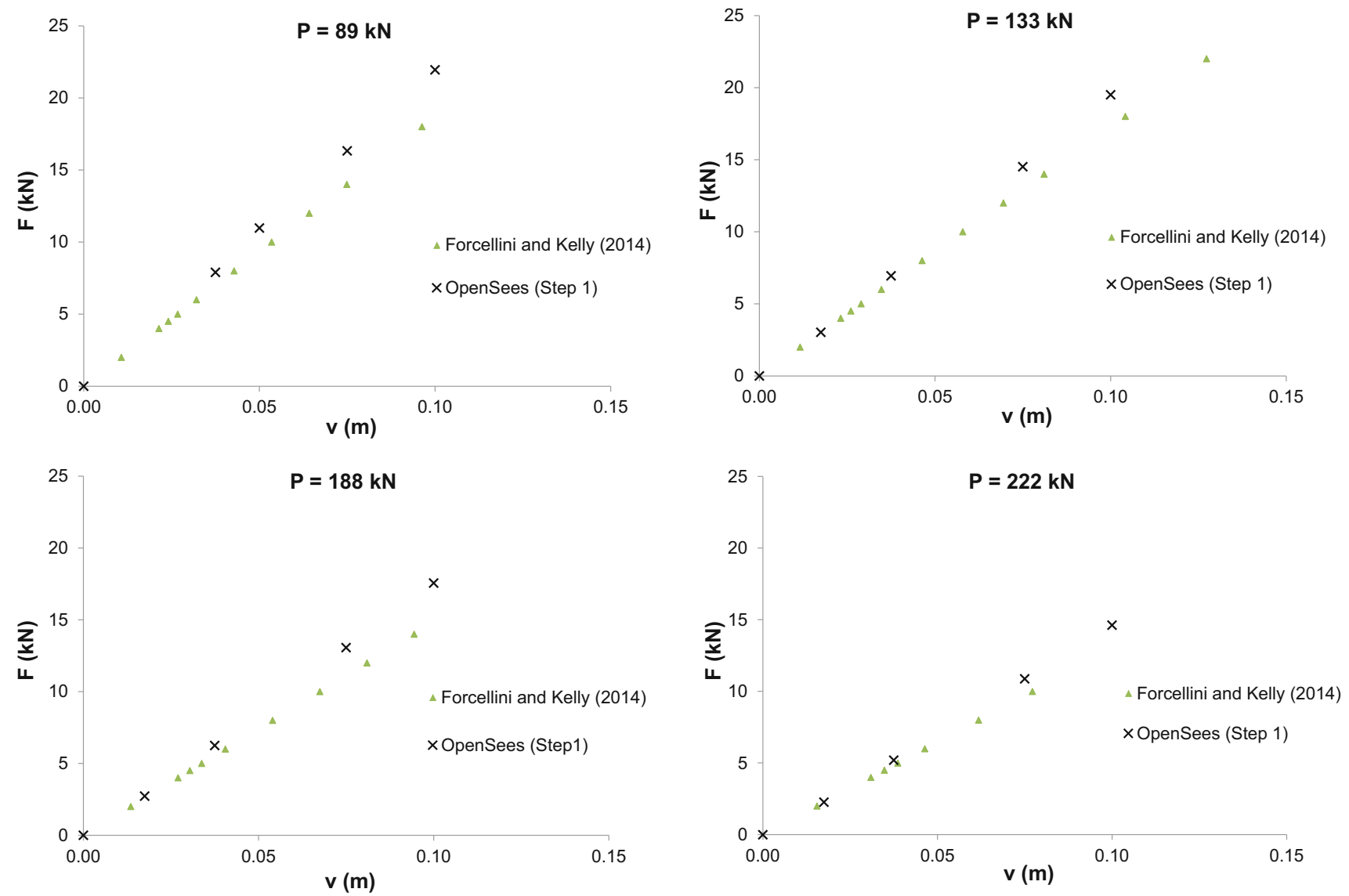

Fig. 8 Shear force-displacement curve (linear model)

Table 2 Characteristics of the material (step 1)

\begin{tabular}{llll}
\hline$G_{\text {rub }}[\mathrm{MPa}]$ & $K_{\text {rub }}[\mathrm{MPa}]$ & $G_{\text {steel }}[\mathrm{MPa}]$ & $K_{\text {steel }}[\mathrm{MPa}]$ \\
\hline 1.40 & 2000 & $8.04 \times 10^{4}$ & $1.74 \times 10^{4}$ \\
\hline
\end{tabular}

possible to see that the curves decrease with increasing axial load, as shown by Nagarajaiah and Ferrell [22]. Secondly, numerical simulations are not able to perform

Table 3 Characteristics of the material (step 2)

\begin{tabular}{lllll}
\hline$G_{\text {rub }}[\mathrm{MPa}]$ & $K_{\text {rub }}[\mathrm{MPa}]$ & $C[\mathrm{MPa}]$ & $p[\%]$ & $n$ \\
\hline 1.40 & 2000 & 4.20 & 0.01 & 20 \\
\hline
\end{tabular}

the degradation after the peak, even if OpenSees takes into account non-linear effects such as large displacements and $p$-delta effects. 

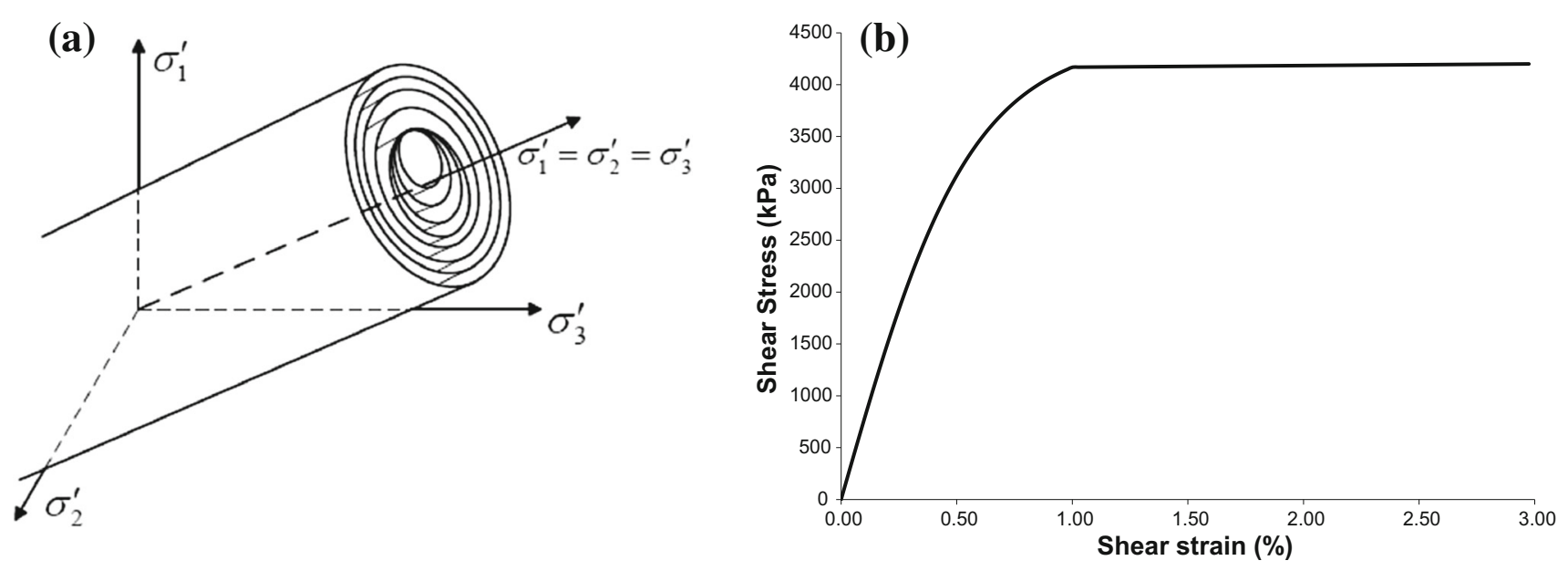

Fig. 9 Von Mises multi-surface in principal stress space (a) and shear stress-strain backbone curve (b) for the rubber (step 2)

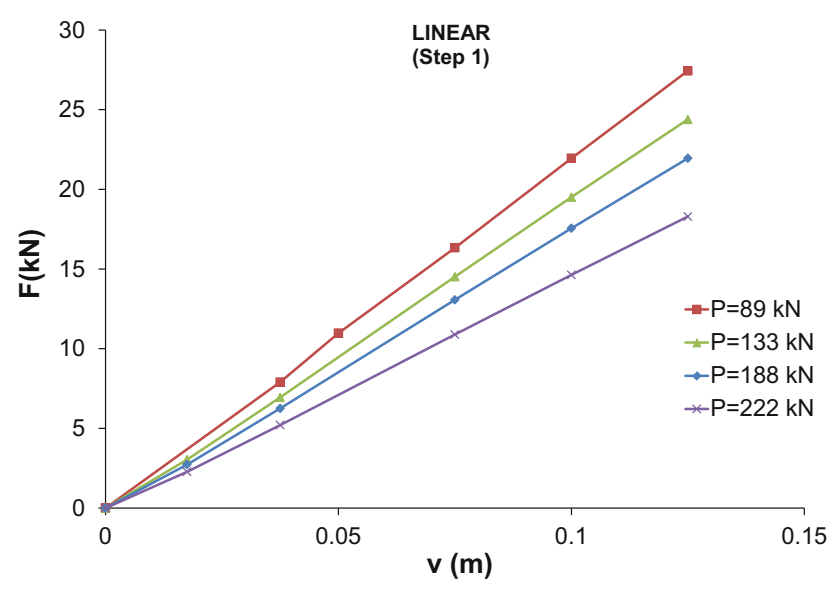

Fig. 10 Shear force-displacement curve (OpenSees)

\section{Discussion}

Figure 11 shows the comparison between the shear forcedisplacement curves obtained by Nagarajaiah and Ferrell [22], the theoretical approach from Forcellini and Kelly [12] and OpenSees simulations with the two steps (linear and non-linear) at various axial loads: 20 kip $(89 \mathrm{kN}), 30$ kip $(133 \mathrm{kN})$ and 40 kip $(188 \mathrm{kN}), 50 \mathrm{kip}(222 \mathrm{kN})$. In particular, numerical results show that the material is able to catch the non-linear increase. Therefore, the parameters with the numerical simulations built up, are shown to be correctly assumed. However, the performed behavior is not able to represent what happens after the peak value. OpenSees is able to model many non-linear effects such as large displacements and $p$-delta effects, but it cannot properly represent the degradation after the peak. This behavior is presumably due to some phenomenon (such as cavitation) that is not described by either the theoretical approach of large displacements or the OpenSees nonlinearities.

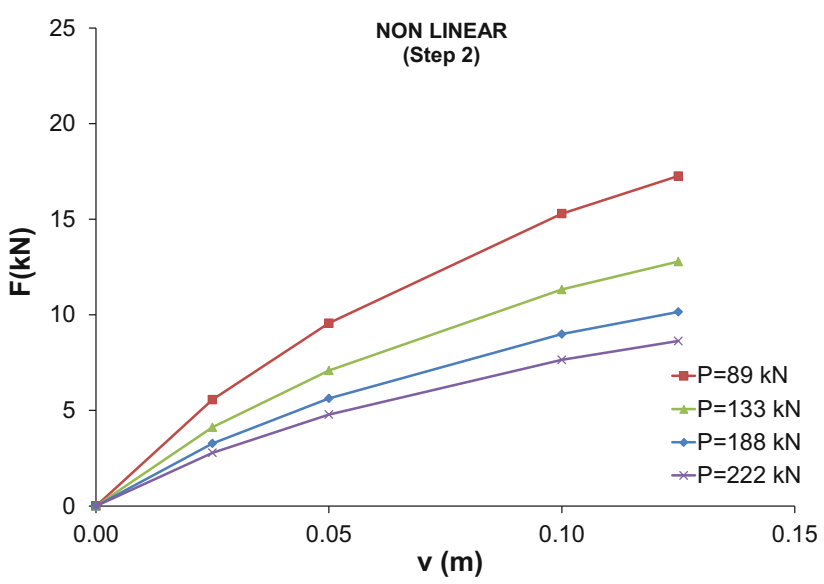

\section{Further development}

The stress level registered during the tests is close to the level at which cavitation is supposed to occur. In particular, cavitation consists of microvoid formations and causes the loss of experimentally observed stiffness when rubber is subjected to hydrostatic tension or dilatant stress [8]. The authors show that cavitation damage can be associated with a significant variation of the bulk modulus K. In this regard, the theoretical approach has to be developed by introducing a more sophisticated definition that can take into account this variation (actually, $\mathrm{K}$ has been considered constant). In addition, Dorfmann and Burtscher [8] have shown that cavitation depends on the dilatational part of the energy density functional. Dorfmann et al. [9] proposed a formulation based on a pseudo-elastic model that can be applied to finite element simulations. In this regard, Kumar et al. [14] have investigated cavitation with numerical investigations by implementing the proposed mathematical model inside OpenSees as two new elements. In particular, 

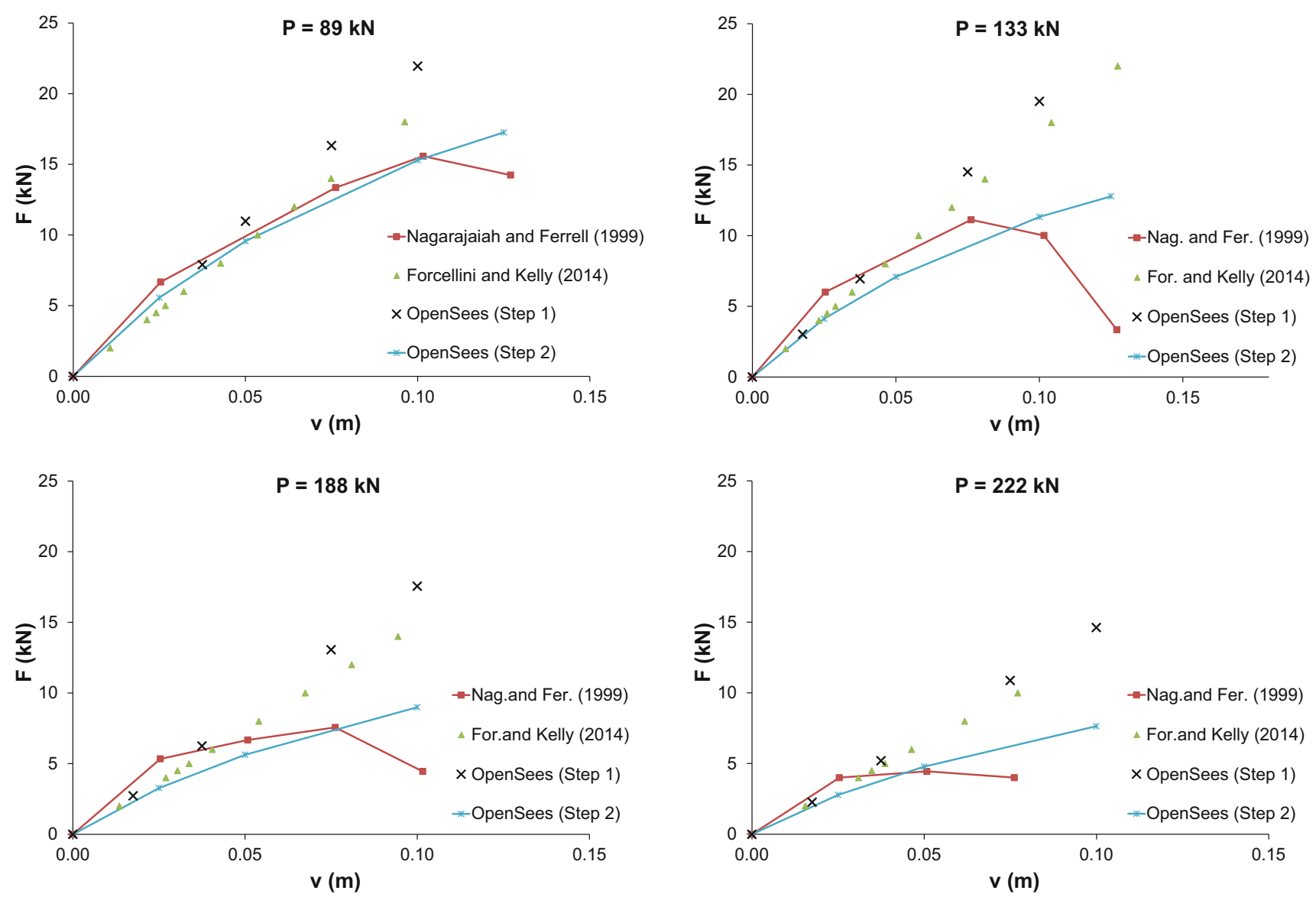

Fig. 11 Shear force-displacement curve

the next step will be to perform 3D numerical simulations by applying a material that will allow considering cavitation. This model will be compared with the elements already implemented by Kumar et al. [14].

\section{Conclusions}

This paper performs a comparison between the theoretical approach proposed by Forcellini and Kelly [12], experimental results from Nagarajaiah and Ferrell [22] and numerical simulations of an elastomeric bearing. The shear force-horizontal displacement, F-v curves have been here reproduced as a function of axial load that has been varied: 20 kip $(89 \mathrm{kN}), 30 \mathrm{kip}(133 \mathrm{kN})$ and $40 \mathrm{kip}(188 \mathrm{kN}), 50$ kip $(222 \mathrm{kN})$. Several steps have been followed.

The theory based on large displacement assumptions has been compared with the lab tests. The comparison shows a good agreement in the first part of the curves where levels of shear load and displacements are small (and linear assumptions can be considered). In particular, it was shown that the effects of the axial load have been performed properly by both the analytical solution and numerical simulations.

Then, a 3D finite element model has been modelled by applying the interface OpenSeesPL. In particular, a selected device has been modelled. Two subsequent assumptions for the material have been considered. First, both materials (rubber and steel) have been considered linear. Then, rubber material has been modelled with a highly hysteretic material, with a Von Mises multi-surface kinematic plasticity model (named Pressure Independent Multiyield).

The comparison between the various results confirms that numerical results have satisfactory agreement with the test results and analytical solution. In this regard, the study does not take into consideration the cavitation phenomenon that can be the most credited cause for the degradation of shear stress. Future work will improve the model in order to take into account cavitation, aiming to be more representative and catch the decreasing part of the curve.

Acknowledgements The author wants to thank Professor James M. Kelly from University of California, Berkeley. His assistance in the definition and the implementation of isolator properties gave determinant contributions to this paper. 


\section{References}

1. Buckle IG, Liu H (1993) Stability of elastomeric seismic isolation systems. Proc., Seminar on Seismic Isolation, Passive Energy Dissipation and Control, Applied Technology Council, Redwood City, CA, pp 293-305

2. Buckle IG, Liu H (1994) Critical loads of elastomeric isolators at high shear strain. Proc., 3rd US-Japan Workshop on Earthquake Protective Systems for Bridges, National Center for Earthquake Engineering Research, Buffalo, NY

3. Buckle I, Nagarajaiah S, Ferrell K (2002) Stability of elastomeric isolation bearings: experimental study. J Struct Eng. doi:10.1061/ (ASCE)0733-9445(2002)128:1(3),3-11

4. Civil Engineering Research Foundation (CERF) (1998) Evaluation findings for Scougal Rubber Corporation high damping rubber bearings. Rep. No. HITEC 98-11 40373, Washington, DC

5. Civil Engineering Research Foundation (CERF) (1998) Evaluation findings for Skellerup base isolation elastomeric bearings. Rep. No. HITEC 98-11 40376, Washington, DC

6. Civil Engineering Research Foundation (CERF) (1998) Evaluation findings for Tekton, Inc., steel rubber bearings. Rep. No. HITEC 98-10 40365, Washington, DC

7. Civil Engineering Research Foundation (CERF) (1999) Summary of evaluation findings for the testing of seismic isolation and energy dissipating devices. Rep. No. 40404, Washington, DC

8. Dorfmann A, Burtscher SL (2000) Aspects of cavitation damage in seismic bearings. J Struct Eng 126(5):573-579

9. Dorfmann A, Fuller KNG, Ogden RW (2002) Shear, compressive and dilatational response of rubberlike solids subject to cavitation damage. Int J Solids Struct 39(2002):1845-1861

10. Forcellini D (2016) Cost Assessment of isolation technique applied to a benchmark bridge with soil structure interaction. Bull Earthq Eng. doi:10.1007/s10518-016-9953-0

11. Forcellini D, Gobbi S (2015) Soil Structure interaction assessment with advanced numerical simulations. Proceedings of computational methods in structural dynamics and earthquake engineering conference (COMPDYN), Crete Island, Greece, 25-27 May 2015

12. Forcellini D, Kelly JM (2014) Analysis of the large deformation stability of elastomeric bearings. J Eng Mech 140(6):04014036

13. Kelly JM, Takhirov SM (2007) Tension buckling in multi-layer elastomeric isolation bearings. J Mech Mater Struct 2(8):1591-1606

14. Kumar M, Whittaker AS, Constatinou MC (2015) Experimental investigation of cavitation in elastomeric seismic isolation bearings. Eng Struct 101(2015):290-305

15. Han X, Kelleher CA, Warn G, Wagener T (2013) Identification of the controlling mechanism for predicting critical loads in elastomeric bearings. J Struct Eng. doi:10.1061/(ASCE)ST.1943541X.0000811,04013016,2013

16. Han X, Warn G, Kasalanati A (2013) Dynamic stability testing of isolation systems composed of elastomeric bearings and implications for design. Proc., Structures Congress 2013, ASCE, Reston, VA, pp 2140-2150
17. Kelly JM (1997) Earthquake-resistant design with rubber. Springer-Verlag, London

18. Lu J, Elgamal A, Yang Z (2011) OpenSeesPL: 3D Lateral pileground interaction. User Manual, Beta 1.0. http://soilquake.net/ openseespl. Accessed 17 Nov 2016

19. Makris N, Zhang J (2004) Seismic response analysis of a highway overcrossing equipped with elastomeric bearings and fluid dampers. J Struct Eng 130(6):830-845

20. Mazzoni S, McKenna F, Scott M H, Fenves GL (2009) Open system for earthquake engineering simulation, user commandlanguage manual. Pacific Earthquake Engineering Research Center, University of California, Berkeley, OpenSees version 2.0. http://opensees.berkeley.edu/OpenSees/manuals/usermanual. Accessed 17 Nov 2016

21. Morgan TA, Mahin SA (2011). The use of base isolation systems to achieve complex seismic performance objectives. Report No. 2011/06, University of California Berkeley, Pacific Earthquake Engineering Research Center, Berkeley, CA

22. Nagarajaiah S, Ferrell K (1999) Stability of elastomeric seismic isolation bearings. J Struct Eng. doi:10.1061/(ASCE)07339445(1999)125:9(946),946-954

23. Prevost JH (1985) A simple plasticity theory for frictional cohesionless soils. J Soil Dyn Earthq Eng 4(1):9-17

24. Sanchez J, Masroor A (2013) Mosqueda G and Ryan K "Static and dynamic stability of elastomeric bearings for seismic protection of structures". J Struct Eng. doi:10.1061/(ASCE)ST.1943541X.0000660,1149-1159

25. Simo JC, Kelly JM (1984) Finite element analysis of the stability of multilayer elastomeric bearings. Eng Struct 6(3):162-174

26. Tongaonkar NP, Jangid RS (2003) Seismic response of isolated bridges with soil-structure interaction. Soil Dyn Earthq Eng 23(4):287-302

27. Ucak A, Tsopelas P (2008) Effect of soil-structure interaction on seismic isolated bridges. J Struct Eng 134(7):1154-1164

28. Vlassis AG, Spyrakos CC (2001) Seismically isolated bridge piers on shallow soil stratum with soil-structure interaction. Comput Struct 79(32):2847-2861

29. Warn G, Weisman J (2011) Parametric finite element investigation of the critical load capacity of elastomeric strip bearings. Eng Struct 33(12):3509-3515

30. Warn GP, Whittaker AS (2006) Property modification factors for seismically isolated bridges. J. Bridge Eng. doi:10.1061/ (ASCE)1084-0702(2006)11:3(371),371-377

31. Warn G, Whittaker A, Constantinou M (2007) Vertical stiffness of elastomeric and lead-rubber seismic isolation bearings. J Struct Eng. doi:10.1061/(ASCE)0733-9445(2007)133: 9(1227), 1227-1236

32. Weisman J, Warn G (2012) Stability of elastomeric and lead rubber seismic isolation bearings. J Struct Eng. doi:10.1061/ (ASCE)ST.1943-541X.0000459,215-223

33. Yang Z, Elgamal A, Parra E (2003) Computational model for cyclic mobility and associated shear deformation. J Geotech Geoenviron Eng 129:1119-1127 